\title{
Expression of CK19, CD105 and CD146 are associated with early metastasis in patients with renal cell carcinoma
}

\author{
XIAOJIE YANG, DONG ZHANG, TIE CHONG, YOUFANG LI, ZIMING WANG and PENG ZHANG \\ Department of Urology, Second Affiliated Hospital of Medical School, Xi'an Jiaotong University, \\ Xi'an, Shaanxi 710061, P.R. China
}

Received August 14, 2016; Accepted January 3, 2018

DOI: $10.3892 / \mathrm{ol} .2018 .7871$

\begin{abstract}
The present study was designed in order to explore the association between the early metastasis of renal cell carcinoma (RCC) and biological markers of tumor cells. A total of 200 patients with RCC, who received a nephrectomy between January 2015 and October 2015, were enrolled in the present study, while 100 healthy patients served as controls. The expression of cytokeratin 19 (CK19), endoglin (CD105) and cluster of differentiation 146 (CD146) were detected using immunohistochemical staining and western blotting. All three markers were highly expressed in tumor tissues compared with adjacent normal tissues. Subsequently, an enzyme-linked immunosorbent assay was used to detect the differential expression of CK19, CD105 and CD146. The results revealed that there was a statistically significant difference in the expression of CK19 and CD105 between the two groups $(\mathrm{P}<0.05)$, whereas CD146 did not exhibit a statistically significant difference. The results of further experiments revealed no significant difference between four time points $(\mathrm{Q} 1,1$ day pre-operation; Q2, 1 day post-operation; Q3, 1 week post-operation; and Q4, 1 month post-operation). Then, subgroup analysis was performed based on whether patients were circulating tumor cell (CTC)-positive or not, and the difference between the Q1 time point and other three time points (Q2-4). The results revealed no difference between the CTC-positive and -negative groups, and no difference between the time points Q1 and Q2. However, the expression of CK19 and CD105 exhibited a significant difference between CTC-positive and CTC-negative groups according to the difference between the time points Q1 and Q3. Furthermore, on the basis of the difference between Q1 and Q4, the expression of CK19, CD105 and
\end{abstract}

Correspondence to: Dr Ziming Wang or Dr Peng Zhang, Department of Urology, Second Affiliated Hospital of Medical School, Xi'an Jiaotong University, 157 West Fifth Road, Xi'an, Shaanxi 710061, P.R China

E-mail: ziming-w@263.net

E-mail: zpbill@aliyun.com

Key words: renal cell carcinoma, cytokeratin 19, endoglin, cluster of differentiation 146, circulating tumor cell, metastasis
CD146 were significantly different $(\mathrm{P}<0.05)$. Taken together, the results suggested that CK19, CD105 and CD146 markers of peripheral blood may be considered to be effective tools to evaluate the early metastasis in a CTC-positive condition. CK19, CD105 and CD146 may be useful for CTC in evaluating the prognosis of patients with RCC, although a larger sample size is necessary for further investigation.

\section{Introduction}

Despite substantial improvement in the survival rates of patients with cancer, cancer remains the most common mortality-associated disease in the United States in 2015 (1). Renal cell carcinoma (RCC) is a lethal malignant tumor type in the urinary system, accounting for $3 \%$ of all malignancies globally in 2015 (2). In China, the incidence of this malignancy is notably increasing. Nephrectomy remains the first-line therapy in patients with a solid tumor (3). However, the frequent metastasis greatly impedes the curative effect following kidney resection. Nearly $30 \%$ of patients with RCC progress to metastatic disease subsequent to radical nephrectomy surgery (4). Numerous independent risk factors, including nodule number, tumor stage [American Joint Committee on Cancer (AJCC, 2010)] (5) and grade, were identified to have a close correlation with the recurrence and metastasis of patients with RCC (6). Nevertheless, these parameters are not absolutely accurate. Hence, the introduction of novelty predictive and prognostic biomarkers will aid oncologists in performing preventative treatment and individual therapy in patients with RCC.

Cytokeratin 19 (CK19) is an epithelial cytoskeleton marker and is highly expressed in epithelial tumor types (7). One previous study has revealed that CK19 may be an appropriate marker for the detection of cancer cells (8). Furthermore, it may function as a prognostic indicator for patients with cancer (9). Endoglin (CD105) was first reported over two decades ago and identified as an accessory receptor for transforming growth factor- $\beta$ (TGF- $\beta$ ) $(10,11)$. It is notably upregulated in endothelial cells and has been considered to be a biomarker for tumor angiogenesis (12). The role of CD105 in the early metastasis of a tumor has gained attention, including in squamous cell carcinoma and pancreatic ductal adenocarcinoma $(13,14)$. In RCC, the function of CD105 remains controversial $(15,16)$. Cluster of differentiation 146 (CD146) is a $113 \mathrm{kD}$ membrane glycoprotein which was first reported in malignant melanoma (17). 
One previous study has reported that CD146 is only expressed in blood vessels and smooth muscle cells (18). Subsequent research has demonstrated that CD146 has multiple functions in development, immunity and angiogenesis (17). CD146 is additionally implicated in the development of the kidney and the nervous system $(19,20)$. However, to the best of our knowledge, there are no previous reports on the association between CD146 expression and RCC metastasis following surgical treatment.

Circulating tumor cells (CTCs) are cells that exist in the blood that have antigenic and/or genetic traits of a specific tumor type (21). They have been used to indicate a poor prognosis in a variety of cancer types, including breast cancer, prostate cancer, colorectal cancer and lung cancer (22-25). The detection of CTCs is easy to implement via peripheral blood samples and may be conducive to improving cancer prognostication and treatment (26).

In the present study, the aim was to explore the association between CK19, CD105 and CD146 and the early metastasis of RCC following surgery, and to evaluate whether the expression of CK19, CD105 and CD146 is associated with the early metastasis of patients with CTC-positive RCC.

\section{Materials and methods}

Ethics statement. The present study was approved by the Ethical Committee of Second Affiliated Hospital of Medical School, Xi'an Jiaotong University (Xi'an, China). The procedures in the present study followed the principles of the Declaration of Helsinki. Written informed consent was obtained from all patients prior to the study.

Patient selection. The present retrospective study recruited 200 RCC cases between January 2015 and October 2015. Of these, there were 100 male and 100 female patients with RCC at stage I, II and III (AJCC, 2010) (5) of the disease (from 70, 122 and 8 patients, respectively) who were accepted for surgical treatment at the Department of Urology, Second Affiliated Hospital of Medical School, Xi'an Jiaotong University (Xi'an, China). Inclusion criteria were as follows: i) Pathological diagnosis confirmed RCC; ii) clinical stage cT1-3 (AJCC, 2010) (5), ready for nephrectomy; iii) distant metastasis were not identified prior kidney resection. Exclusion criteria were as follows: i) Patients with RCC with other malignancies; ii) patients who had undergone chemotherapy or radiotherapy prior to surgery. A total of 100 patients with no sign of tumor in pathology were additionally included as the control group. The mean age of the patients with RCC and without were 60 years (age range from 40 to 79 years) and 61.36 years (age range from 39 to 75 years), respectively.

Blood sampling and tumor tissues collecting. Once informed consent was obtained from all patients, $10 \mathrm{ml}$ peripheral venous blood samples were collected at four different times (Q1, 1 day pre-operation; Q2, 1 day post-operation; Q3, 1 week post-operation; and Q4, 1 month post-operation), transferred to the laboratory and used for further experiments. Tumor tissues and adjacent normal tissues were resected during surgery, collected and stored at $-80^{\circ} \mathrm{C}$ for subsequent experiments.
Hematoxylin-eosin $(H \& E)$ staining. All surgical specimens were collected and transferred to the laboratory. Subsequently, the samples were fixed using $4 \%$ paraformaldehyde for $48 \mathrm{~h}$ at room temperature. Then, the samples were embedded in paraffin and submitted to $\mathrm{H} \& \mathrm{E}$ staining at room temperature for $48 \mathrm{~h}$.

Immunohistochemistry. Tumor samples ( $4 \mu \mathrm{m}$ thick) were fixed with $4 \%$ paraformaldehyde at room temperature for $48 \mathrm{~h}$ and embedded in paraffin. Following deparaffinization and rehydration as follows: Ethanol for 15 min 3 times, $95 \%$ ethanol for $2 \mathrm{~h}$ twice, $90 \%$ ethanol for $1 \mathrm{~h}, 80 \%$ ethanol for $1 \mathrm{~h}$ and $70 \%$ ethanol for $30 \mathrm{~min}$, the CD105 antigen was retrieved using a citric acid buffer (pH 6.0; Boster Biological Technology, Pleasanton, CA, USA). Subsequently, the samples were blocked using endogenous peroxidase for $30 \mathrm{~min}$ at room temperature. Following washing with potassium-free phosphate-buffered saline (PBS) buffer 3 times, the samples were incubated with monoclonal antibodies against CK19 (cat no. 13092), CD105 (cat no. 14606) and CD146 (cat no. 13475) (Cell Signaling Technology, Inc., Danvers, MA, USA; dilution 1:100) overnight at $4^{\circ} \mathrm{C}$. Subsequent to rewarming, the samples were incubated with the corresponding secondary antibodies [anti-mouse IgG (cat no. BA1051) and anti-rabbit IgG (cat no. BA1055) horseradish peroxidase-conjugated secondary antibodies; Boster Biological Technology; dilution 1:1,000] for $1 \mathrm{~h}$ at room temperature. Then the sections were stained using Mayer's hematoxylin for $5 \mathrm{~min}$ at room temperature, followed by dehydration (70\% ethanol for $30 \mathrm{~min}, 80 \%$ ethanol for $1 \mathrm{~h}, 90 \%$ ethanol for $1 \mathrm{~h}, 95 \%$ ethanol for $2 \mathrm{~h}$ twice and ethanol for $15 \mathrm{~min}$ 3 times) and transparency. Finally, the sections were mounted with neutral resins and visualized using a light microscope (x20 and $\mathrm{x} 40$ ).

Western blotting. Briefly, total proteins were washed using PBS buffer 3 times and extracted using RIPA lysis buffer $(50 \mathrm{mM}$ Tris- $\mathrm{HCl} \mathrm{pH}$ 7.4, $150 \mathrm{mM} \mathrm{NaCl}, 0.1 \%$ Triton X-100, 1\% PMSF) for $10 \mathrm{~min}$ at $4^{\circ} \mathrm{C}$. Following centrifugation for $15 \mathrm{~min}$ at $14,000 \mathrm{x} \mathrm{g}$ at $4^{\circ} \mathrm{C}$. Protein concentration was determined using a Bicinchoninic Acid Assay kit (Sigma-Aldrich; Merck KGaA, Darmstadt, Germany). Proteins were separated using sodium dodecyl sulfate-polyacrylamide gel electrophoresis (10\%) and transferred to polyvinylidene difluoride membranes. Then, the membranes were blocked with $5 \%$ nonfat milk for $1 \mathrm{~h}$ at room temperature and incubated with primary antibodies against CK19 (cat no. 13092), CD105 (cat no. 14606) and CD146 (cat no. 13475) (Cell Signaling Technology, Inc.; dilution 1:1,000) overnight at $4^{\circ} \mathrm{C}$. The membranes were washed 3 times using tris-buffered saline with Tween-20 buffer $(10 \mathrm{mM}$ Tris- $\mathrm{HCl}$ $\mathrm{pH} 7.4,150 \mathrm{mM} \mathrm{NaCl}$ and $0.1 \%$ Tween-20) and incubated with horseradish peroxidase-conjugated secondary antibodies [anti-mouse IgG (cat no. BA1051) and anti-rabbit IgG (cat no. BA1055); Boster Biological Technology; dilution 1:1,000] at room temperature for $1 \mathrm{~h}$. Finally, the protein bands were visualized using an enhanced chemiluminescence substrate.

Enzyme-linked immunosorbent assay (ELISA). Blood samples $(5 \mathrm{ml})$ were collected from patients and controls. Following centrifugation at $4^{\circ} \mathrm{C}$ at $1,200 \mathrm{x} \mathrm{g}$ for $10 \mathrm{~min}$, the serum levels of CK19, CD105 and CD146 were determined using an ELISA kit (R\&D Systems, Inc., Minneapolis, MN, USA) according 
Table I. Clinical characteristics of patients with RCC.

\begin{tabular}{|c|c|c|}
\hline Variables & Frequency & Percent $(\%)$ \\
\hline \multicolumn{3}{|l|}{ Age (years) } \\
\hline Median age (range) & $60(40-79)$ & \\
\hline \multicolumn{3}{|l|}{ Sex } \\
\hline Female & 100 & 50.0 \\
\hline Male & 100 & 50.0 \\
\hline \multicolumn{3}{|l|}{ Tumor grade } \\
\hline I & 70 & 35.0 \\
\hline II & 122 & 61.0 \\
\hline III & 8 & 4.0 \\
\hline \multicolumn{3}{|l|}{ TNM stage } \\
\hline T1aN0M0 & 72 & 36.0 \\
\hline T1bN0M0 & 98 & 49.0 \\
\hline T2aNOM0 & 23 & 11.5 \\
\hline T3aNOMO & 7 & 3.5 \\
\hline \multicolumn{3}{|l|}{ Pathological type } \\
\hline Clear cell RCC & 166 & 83.0 \\
\hline Papillary RCC & 34 & 17.0 \\
\hline \multicolumn{3}{|l|}{ Surgical } \\
\hline NSS & 135 & 67.5 \\
\hline $\mathrm{RN}$ & 65 & 32.5 \\
\hline \multicolumn{3}{|l|}{ СТC } \\
\hline Positive & 90 & 45.0 \\
\hline Negative & 110 & 55.0 \\
\hline
\end{tabular}

RCC, renal cell carcinoma; T, tumor; N, node; M, metastasis; NSS, nephron-sparing surgery; RN, radical nephrectomy; CTC, circulating tumor cells.

to the manufacturer's protocol. Each sample was detected in duplicate.

CTC analysis. The CellSearch system (Janssen Diagnostics LLC, Raritan, NJ, USA) was used for the detection and evaluation of CTCs according to the manufacturer's protocol. A blood volume of $7.5 \mathrm{ml}$ was prepared for each sample analysis.

Statistical analysis. All analyses were calculated using SPSS 19.0 software (IBM Corp., Armonk, NY, USA). The results are represented as the mean \pm standard deviation. A paired Student's t-test was used for the analysis of numerical data. $\mathrm{P}<0.05$ was considered to indicate a statistically significant difference.

\section{Results}

Patient characteristics. The present study analyzed 200 patients with RCC who underwent nephrectomy at the Second Affiliated Hospital of Medical School, Xi'an Jiaotong University between January 2015 and October 2015. An additional 100 patients without RCC were recruited as controls. The mean age of the patient and control groups were 60 years (ranging from 40 to 79 years) and 61.36 years (ranging from
Table II. CK19, CD105 and CD146 expression between patient and control groups.

\begin{tabular}{lccc}
\hline Variables & Patients group & Control group & P-value \\
\hline CK19 & $3.29 \pm 1.89$ & $2.73 \pm 1.01$ & 0.038 \\
CD105 & $6.07 \pm 3.18$ & $4.90 \pm 1.91$ & 0.014 \\
CD146 & $204.90 \pm 100.63$ & $217.18 \pm 80.26$ & 0.471 \\
\hline
\end{tabular}

CK19, cytokeratin 19; CD105, endoglin; CD146, cluster of differentiation 146.

Table III. Expression of CK19, CD105 and CD146 in patients with a CTC-positive condition according to the difference between the time points of Q1 and Q3.

\begin{tabular}{lccc}
\hline Variables & $\begin{array}{c}\text { CTC-positive } \\
\text { group }\end{array}$ & Control group & P-value \\
\hline CK19 & $0.667 \pm 0.877$ & $-0.176 \pm 0.266$ & 0.010 \\
CD105 & $0.760 \pm 0.849$ & $-0.446 \pm 0.346$ & 0.001 \\
CD146 & $19.495 \pm 34.640$ & $-19.390 \pm 113.124$ & 0.337
\end{tabular}

CTC, circulating tumor cells; CK19, cytokeratin 19; CD105, endoglin; CD146, cluster of differentiation 146.

39 to 75 years), respectively. All patients had a non-metastatic form of the disease (stage I-III) (Table I).

CK19, CD105 and CD146 expression. Firstly, H\&E staining was used to confirm whether the resected tissues were from the solid tumor. The results revealed notable tumor cell clusters different from the adjacent epithelial cells (Fig. 1A). Subsequently, the expression of CK19, CD105 and CD146 in tumor tissues and adjacent normal tissues were detected using immunohistochemistry staining. Positive CK19 staining was observed in the cytoplasm of the tumor cells of 200 patients (Fig. 1B). The staining of the tumor cells of all patients was strong and cytoplasmic. The distribution of CD105 and CD146 staining were also located in the cytoplasm of tumor cells (Fig. 1B). To further explore the differential expression of CK19, CD105 and CD146 between tumor and normal tissues, western blotting was performed. The results demonstrated that CK19, CD105 and CD146 are highly expressed in tumor tissues compared with their corresponding adjacent normal tissues (Fig. 1C).

Association between the early metastasis of patients with RCC and the expression of CK19, CD105 and CD146. The application of ELISA to analyze biomarker expression in the peripheral blood of patients with a tumor is an emerging concept in the management of cancer (25). Thus, the expression of CK19, CD105 and CD146 were detected at four different time points in patient and control groups using ELISA (Q1, 1 day pre-operation; Q2, 1 day post-operation; Q3, 1 week post-operation; and Q4, 1 month post-operation). The results revealed that there is a significant difference between the 


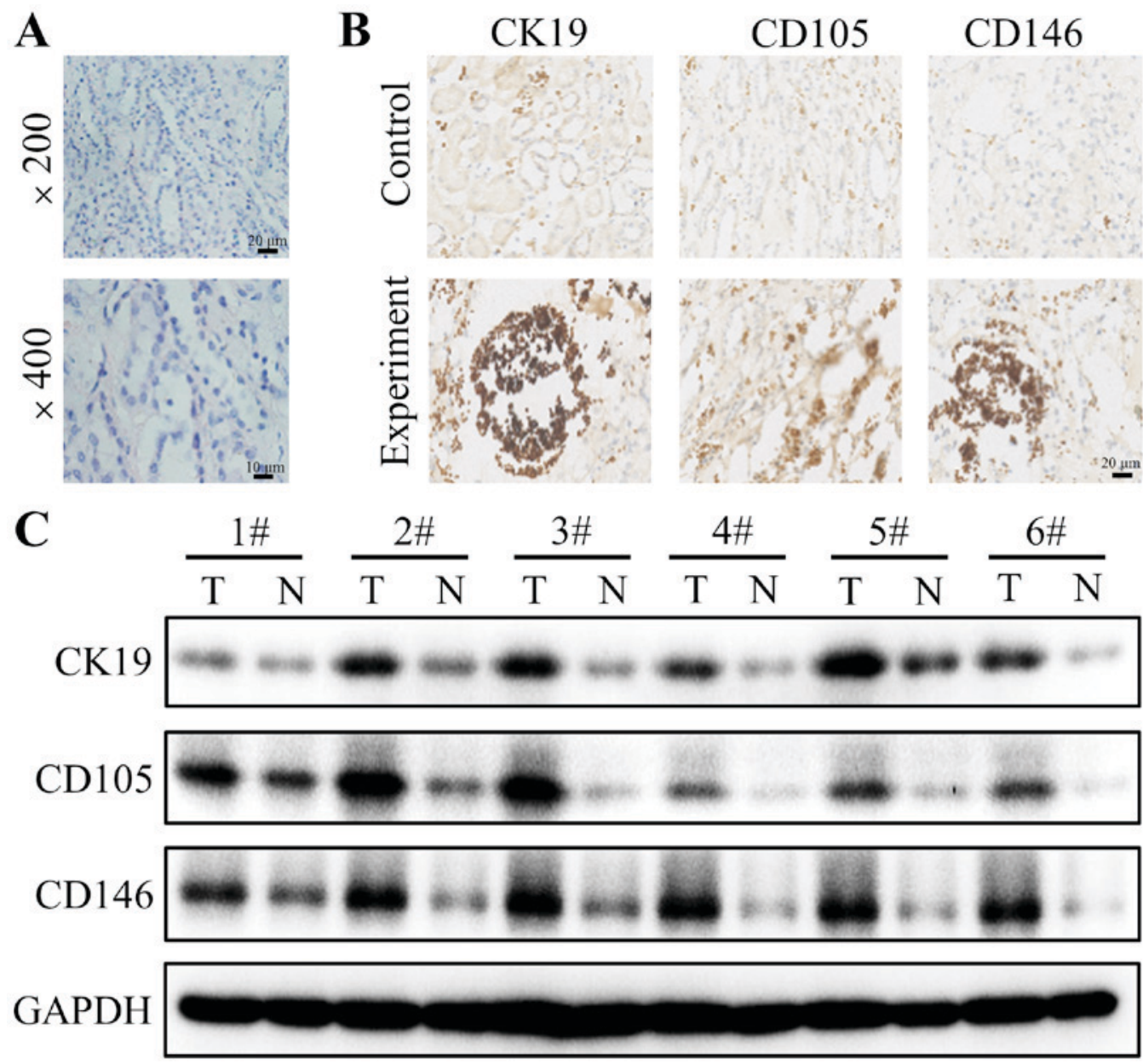

Figure 1. CK19, CD105 and CD146 expression in renal cell carcinoma tissues. (A) Representative tumor samples with hematoxylin-eosin staining. (B) Representative sections of CK19, CD105 and CD146 in tumor tissues compared with adjacent normal tissues, which were detected using immunohistochemical staining. (C) Representative blots extracted from tumor tissues and normal tissues were subjected to western blotting for CK19, CD105 and CD146. GAPDH was used as a loading control. Each number corresponds to a different patient. Representative blots of three experiments are shown. CK19, cytokeratin 19; CD105, endoglin; CD146, cluster of differentiation 146.

Table IV. Expression of CK19, CD105 and CD146 in patients with a CTC-positive condition according to the difference between the time points of Q1 and Q4.

\begin{tabular}{lccc}
\hline Variables & $\begin{array}{c}\text { CTC positive } \\
\text { group }\end{array}$ & Control group & P-value \\
\hline CK19 & $1.082 \pm 1.555$ & $-0.026 \pm 0.163$ & 0.038 \\
CD105 & $1.403 \pm 2.395$ & $-0.201 \pm 0.120$ & 0.049 \\
CD146 & $57.943 \pm 56.742$ & $-28.270 \pm 79.113$ & 0.015
\end{tabular}

CTC, circulating tumor cells; CK19, cytokeratin 19; CD105, endoglin; CD146, cluster of differentiation 146.

expression of CK19, CD105 between the patient and control groups $(\mathrm{P}<0.05)$, but not for CD146 (Table II). Then, the differential expressions of CK19, CD105 and CD146 between all four time points were investigated through pairwise comparison. The results indicated no statistically significant differences (data not shown).

CTCs have been identified as a predictor of early metastasis in patients with cancer (26). Based on whether patients
Table V. Expression of CK19, CD105 and CD146 in patients with a CTC-negative condition according to the difference between the time points of Q1 and Q4.

\begin{tabular}{lccc}
\hline Variables & $\begin{array}{c}\text { CTC negative } \\
\text { group }\end{array}$ & Control group & P-value \\
\hline CK19 & $0.100 \pm 1.448$ & $-0.026 \pm 0.163$ & 0.788 \\
CD105 & $-0.471 \pm 0.566$ & $-0.201 \pm 0.120$ & 0.156 \\
CD146 & $-28.790 \pm 44.910$ & $-28.270 \pm 79.113$ & 0.98
\end{tabular}

CTC, circulating tumor cells; CK19, cytokeratin 19; CD105, endoglin; CD146, cluster of differentiation 146.

were CTC-positive or CTC-negative, subgroup analysis was performed. The results demonstrated that the expression of CK19, CD105 and CD146 was not significantly different between CTCs-positive and CTC-negative groups or between four time points using pairwise comparison (data not shown). These results are in accordance with previous results in the present study. Under a CTC-positive condition, the expression of CK19, CD105 and CD146 in patient and control groups was 
detected and compared according to the difference between the time point Q1 and the other three time points (Q2-4). The results of the present study suggested that the three biomarkers had no statistical difference in the patient group compared with the control group based on the difference between the Q2 and Q1 time points (data not shown). A significant difference between the difference of expression of CK19 and CD105 between the Q1 and Q3 time points of CTC-positive patient and non-RCC control groups was identified $(\mathrm{P}<0.05$; Table III). However, no significant difference was identified with CD146. On the basis of the difference between Q1 and Q4, the expressions of all three markers exhibited a statistically significant difference $(\mathrm{P}<0.05$; Table IV). Nevertheless, no significant difference was identified in a CTC-negative condition ( $\mathrm{P}>0.05$; Table V).

\section{Discussion}

Tendency to invade and transfer is one of the obstacles in the treatment of RCC. Clinical parameters including Fuhrman stage may not entirely reflect prognosis and early metastasis (27). Patients may have a recurrence or metastasis with a low-grade and early-stage tumor following surgery. Thus, oncologists and clinicians produced insight into alternative or complementary indicators, expecting to predict disease progression and early prognosis more accurately (28). The aim of the present study was to explore peripheral blood biomarkers (CK19, CD105 and CD146) for the early metastasis of RCC following surgery.

CK19 is a characteristic intermediate filament of epithelial cells, which has gained attention as a marker for micro-metastasis (29). It has been reported that CK 19 may be detected in the tumor cells of patients with breast cancer (30). Although additional validation studies are essential, the present study demonstrated that CK19 is highly expressed in tumor tissues compared with that in normal tissues, which were confirmed using immunohistochemical staining and western blotting. CD105, a co-receptor of TGF- $\beta$, is implicated in tumor proliferation, migration and differentiation (31). It has been reported to be a marker of tumor neovascularization, and to provide prognostic data (31). It has been demonstrated that the high expression of CD105 is closely correlated with a more favorable prognosis compared with lower expression (32). However, other studies have demonstrated that the high CD105 expression is positively associated with a poorer progression-free survival (33). In the present study, CD105 expression in tumor tissues was greater compared with that in normal tissues, which was consistent with the latter. CD146 was revealed to participate in cancer progression. It may enhance cancer migration and invasion in melanoma, gallbladder adenocarcinoma and breast cancer (34-36). Furthermore, CD105 had been considered to be an indicator of early metastasis including in gastric cancer and lung cancer (37). However, the expression of CD146 was greater in the intermediate/high grade of oral mucoepidermoid carcinoma compared with that in patients with local recurrence and distant metastasis (38). To the best of our knowledge, the role of CD146 in RCC cells had not yet been explored. In the present study, CD146 expression in tumor tissues was revealed to be higher compared with that in normal tissues, which corresponded with the results of a previous study (37).
In the subsequent experiment, the results indicated that the expressions of CK19 and CD105 had statistically significant differences between two groups $(\mathrm{P}<0.05)$, but no such significant difference was identified for CD146. Further experiments revealed no significant difference between four time points (data not shown). Furthermore, CTCs were examined, a crucial blood biomarker in cancer (26). CTC clusters have been reported to be present in patients with metastatic colorectal cancer and prostate cancer, and have a positive correlation with decreased survival in lung cancer and breast cancer $(39,40)$. Furthermore, the CTC clusters may indicate a poor outcome in breast cancer via detection using the CellSearch system (41). In view of the indicated role of CTCs on tumor prognosis and early metastasis, subgroup analysis was performed based on whether the patients were CTC positive or not, and the difference between the point of Q1 and other three points (Q2-4). Similar to the results presented before, the results revealed no statistically significant difference between the CTC-positive or -negative condition, and in the difference between the time points Q1 and Q2 (data not shown). Nevertheless, the expression of CK19 and CD105 exhibited a significant difference with a CTC-positive condition according to the difference between the time points Q1 and Q3 $(\mathrm{P}<0.05)$. Furthermore, on the basis of the difference between Q1 and Q4, the expression of CK19, CD105 and CD146 were significantly different $(\mathrm{P}<0.05)$. The results concluded that CK19, CD105 and CD146 could not be used individually to predict the early metastasis of patients with RCC subsequent to surgery. The expressions of CK19, CD105, and CD146 at Q2 (1 day post-operation) may not accurately reflect the levels of biomarkers following surgery, due to the state of stress caused by surgical trauma, which resulted in no statistical difference between the CTC-positive condition in the difference between the point of Q1 and Q2. But at the Q3 time point (1 week post-operation), patients had recovered from the surgery. The expression of CK19 and CD105 exhibited a significant difference with a CTC-positive condition based on the difference between Q1 and Q3 $(\mathrm{P}<0.05)$, although CD146 did not. Furthermore, a statistically significant difference was present in the expression of CK19, CD105 and CD146 on the basis of the difference between Q1 and Q4 $(\mathrm{P}<0.05)$, indicating that CK19, CD105 and CD146 may be novel predictors for the early metastasis of CTC-positive condition in the difference between Q1 and Q3/Q4. Additionally, CK19, CD105 and CD146 may be auxiliary indicators for CTCs to estimate the prognosis of patients with RCC.

Altogether, the results suggest that CK19, CD105 and CD146 markers of peripheral blood may be considered to be effective tools to evaluate the early metastasis of patients with a CTC-positive condition between Q1 and Q3/Q4. CK19, CD105 and CD146 may be useful for CTCs to evaluate the prognosis of patients with RCC, although more widespread studies with larger scale samples are required in order to verify the results of the present study. As a nonsurgical strategy, CK19, CD105 and CD146 may be the potential targets for treatment of RCC.

\section{Acknowledgements}

The present study was supported by the Key Science and Technology Program of Shaanxi Province (grant no. 2011K12-34). 


\section{Competing interests}

The authors declare that they have no competing interests.

\section{References}

1. Siegel RL, Miller KD and Jemal A: Cancer statistics, 2016. CA Cancer J Clin 66: 7-30, 2016.

2. Siegel RL, Miller KD and Jemal A: Cancer Statistics, 2015. CA Cancer J Clin 65: 5-29, 2015

3. Heuer R, Gill IS, Guazzoni G, Kirkali Z, Marberger M, Richie JP and de la Rosette JJ: A critical analysis of the actual role of minimally invasive surgery and active surveillance for kidney cancer Eur Urol 57: 223-232, 2010.

4. Ritchie AW and Chisholm GD: The natural history of renal carcinoma. Semin Oncol 10: 390-400, 1983.

5. Edge SB, Byrd DR, Compton CC, Fritz AG, Greene FL and Trotti A: AJCC cancer staging manual. 7th ed. Springer-Verlag, New York, pp. 547-560, 2009.

6. Chin AI, Lam JS, Figlin RA and Belldegrun AS: Surveillance strategies for renal cell carcinoma patients following nephrectomy. Rev Urol 8: 1-7, 2006.

7. Sun DW, Zhang YY, Sun XD, Chen YG, Qiu W, Ji M and Lv GY: Prognostic value of cytokeratin 19 in hepatocellular carcinoma: A meta-analysis. Clin Chim Acta 448: 161-169, 2015.

8. Schmitt AM, Anlauf M, Rousson V, Schmid S, Kofler A, Riniker F, Bauersfeld J, Barghorn A, Probst-Hensch NM, Moch H, et al: WHO 2004 criteria and CK19 are reliable prognostic markers in pancreatic endocrine tumors. Am J Surg Pathol 31: 1677-1682, 2007.

9. Stathopoulos EN, Sanidas E, Kafousi M, Mavroudis D, Askoxylakis J, Bozionelou V, Perraki M, Tsiftsis D and Georgoulias V: Detection of CK-19 mRNA-positive cells in the peripheral blood of breast cancer patients with histologically and immunohistochemically negative axillary lymph nodes. Ann Oncol 16: 240-246, 2005.

10. Quackenbush EJ and Letarte M: Identification of several cell surface proteins of non-T, non-B acute lymphoblastic leukemia by using monoclonal antibodies. J Immunol 134: 1276-1285, 1985.

11. Wong SH, Hamel L, Chevalier S and Philip A: Endoglin expression on human microvascular endothelial cells association with betaglycan and formation of higher order complexes with TGF-beta signalling receptors. Eur J Biochem 267: 5550-5560, 2000.

12. Nassiri F, Cusimano MD, Scheithauer BW, Rotondo F, Fazio A, Yousef GM, Syro LV, Kovacs K and Lioyd RV: Endoglin (CD105): A review of its role in angiogenesis and tumor diagnosis, progression and therapy. Anticancer Res 31: 2283-2290, 2011.

13. Nair S, Nayak R, Bhat K, Kotrashetti VS and Babji D: Immunohistochemical expression of CD105 and TGF-beta1 in oral squamous cell carcinoma and adjacent apparently normal oral mucosa and its correlation with clinicopathologic features. Appl Immunohistochem Mol Morphol 24: 35-41, 2016.

14. Lytras D, Leontara V, Kefala M, Foukas PG, Giannakou N, Pouliakis A, Dervenis C, Panayiotides IG and Karakitsos P: Microvessel landscape assessment in pancreatic ductal adenocarcinoma: Unclear value of targeting endoglin (CD105) as prognostic factor of clinical outcome. Pancreas 44: 87-92, 2015.

15. Sandlund J, Hedberg Y, Bergh A, Grankvist K, Ljungberg B and Rasmuson T: Endoglin (CD105) expression in human renal cell carcinoma. BJU Int 97: 706-710, 2006.

16. Dubinski W, Gabril M, Iakovlev VV, Scorilas A, Youssef YM, Faragalla H, Kovacs K, Rotondo F, Metias S, Arsanious A, et al: Assessment of the prognostic significance of endoglin (CD105) in clear cell renal cell carcinoma using automated image analysis. Hum Pathol 43: 1037-1043, 2012

17. Wang Z and Yan X: CD146, a multi-functional molecule beyond adhesion. Cancer Lett 330: 150-162, 2013

18. Sers C, Riethmuller G and Johnson JP: MUC18, a melanoma-progression associated molecule, and its potential role in tumor vascularization and hematogenous spread. Cancer Res 54: 5689-5694, 1994.

19. Takaha N, Taira E, Taniura H, Nagino T, Tsukamoto $Y$, Matsumoto T, Kotani T, Sakuma S and Miki N: Expression of gicerin in development, oncogenesis and regeneration of the chick kidney. Differentiation 58: 313-320, 1995.

20. Taira E, Kohama K, Tsukamoto Y, Okumura S and Miki N: Gicerin/CD146 is involved in neurite extension of NGF-treated PC12 cells. J Cell Physiol 204: 632-637, 2005.
21. Harris L, Fritsche H, Mennel R, Norton L, Ravdin P, Taube S, Somerfield MR, Hayes DF and Bast RC Jr; American Society of Clinical Oncology: American Society of Clinical Oncology 2007 update of recommendations for the use of tumor markers in breast cancer. J Clin Oncol 25: 5287-5312, 2007.

22. Saloustros E and Mavroudis D: Cytokeratin 19-positive circulating tumor cells in early breast cancer prognosis. Future Oncol 6: 209-219, 2010

23. de Bono JS, Scher HI, Montgomery RB, Parker C, Miller MC, Tissing H, Doyle GV, Terstappen LW, Pienta KJ and Raghavan D: Circulating tumor cells predict survival benefit from treatment in metastatic castration-resistant prostate cancer. Clin Cancer Res 14: 6302-6309, 2008.

24. Cohen SJ, Punt CJ, Iannotti N, Saidman BH, Sabbath KD, Gabrail NY, Picus J, Morse MA, Mitchell E, Miller MC, et al: Prognostic significance of circulating tumor cells in patients with metastatic colorectal cancer. Ann Oncol 20: 1223-1229, 2009.

25. Hou JM, Krebs MG, Lancashire L, Sloane R, Backen A, Swain RK, Priest LJ, Greystoke A, Zhou C, Morris K, et al: Clinical significance and molecular characteristics of circulating tumor cells and circulating tumor microemboli in patients with small-cell lung cancer. J Clin Oncol 30: 525-532, 2012.

26. Lianidou ES, Markou A and Strati A: The role of CTCs as tumor biomarkers. Adv Exp Med Biol 867: 341-367, 2015.

27. Volpe A and Patard JJ: Prognostic factors in renal cell carcinoma. World J Urol 28: 319-327, 2010

28. Aceto N, Bardia A, Miyamoto DT, Donaldson MC, Wittner BS, Spencer JA, Yu M, Pely A, Engstrom A, Zhu H, et al: Circulating tumor cell clusters are oligoclonal precursors of breast cancer metastasis. Cell 158: 1110-1122, 2014

29. Yu XF, Yang HJ, Lei L, Wang C and Huang J: CK19 mRNA in blood can predict non-sentinel lymph node metastasis in breast cancer. Oncotarget 7: 30504-30510, 2016.

30. Alix-Panabières C, Vendrell JP, Slijper M, Pellé O, Barbotte E, Mercier G, Jacot W, Fabbro M and Pantel K: Full-length cytokeratin-19 is released by human tumor cells: A potential role in metastatic progression of breast cancer. Breast Cancer Res 11: R39, 2009.

31. Smith SJ, Tilly H, Ward JH, Macarthur DC, Lowe J, Coyle B and Grundy RG: CD105 (Endoglin) exerts prognostic effects via its role in the microvascular niche of paediatric high grade glioma. Acta Neuropathol 124: 99-110, 2012.

32. Tanaka F, Otake Y, Yanagihara K, Kawano Y, Miyahara R, Li M, Ishikawa $\mathrm{S}$ and Wada $\mathrm{H}$ : Correlation between apoptotic index and angiogenesis in non-small cell lung cancer: Comparison between CD105 and CD34 as a marker of angiogenesis. Lung Cancer 39: 289-296, 2003.

33. Nikiteas NI, Tzanakis N, Theodoropoulos G, Atsaves V, Christoni Z, Karakitsos P, Lazaris AC, Papachristodoulou A, Klonaris C and Gazouli M: Vascular endothelial growth factor and endoglin (CD-105) in gastric cancer. Gastric Cancer 10:12-17, 2007.

34. Lei X, Guan CW, Song Y and Wang H: The multifaceted role of CD146/MCAM in the promotion of melanoma progression. Cancer Cell Int 15: 3, 2015.

35. Wang W, Yang ZL, Liu JQ, Jiang S and Miao XY: Identification of CD146 expression, angiogenesis, and lymphangiogenesis as progression, metastasis, and poor-prognosis related markers for gallbladder adenocarcinoma. Tumour Biol 33: 173-182, 2012.

36. Zabouo G, Imbert AM, Jacquemier J, Finetti P, Moreau T, Esterni B, Birnbaum D, Bertucci F and Chabannon C: CD146 expression is associated with a poor prognosis in human breast tumors and with enhanced motility in breast cancer cell lines. Breast Cancer Res 11: R1, 2009.

37. Koyama Y, Okayama H, Kumamoto K, Saito K, Nakamura I, Ohki S and Takenoshita S: Overexpression of endoglin (CD105) is associated with recurrence in radically resected gastric cancer. Exp Ther Med 1: 627-633, 2010.

38. Pires FR, Shih IeM, da Cruz Perez DE, de Almeida OP and Kowalski LP: Mel-CAM (CD146) expression in parotid mucoepidermoid carcinoma. Oral Oncol 39: 277-281, 2003.

39. Molnar B, Ladanyi A, Tanko L, Sréter L and Tulassay Z: Circulating tumor cell clusters in the peripheral blood of colorectal cancer patients. Clin Cancer Res 7: 4080-4085, 2001.

40. Brandt B, Junker R, Griwatz C, Heidi S, Brinkmann O, Semjonow A, Assmann G and Zanker KS: Isolation of prostate-derived single cells and cell clusters from human peripheral blood. Cancer Res 56: 4556-4561, 1996.

41. Méhes G, Witt A, Kubista E and Ambros PF: Circulating breast cancer cells are frequently apoptotic. Am J Pathol 159: 17-20, 2001.

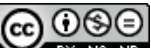

This work is licensed under a Creative Commons

Attribution-NonCommercial-NoDerivatives 4.0 International (CC BY-NC-ND 4.0) License. 